\section{Aquaculture}

September 2008, Volume 282 (1-4) : Pages 97-103

http://dx.doi.org/10.1016/j.aquaculture.2008.06.010

(c) 2008 Published by Elsevier B.V.
Archimer, archive institutionnelle de l'Ifremer http://www.ifremer.fr/docelec/

\title{
Pavlova lutheri: Production, preservation and use as food for Crassostrea gigas larvae
}

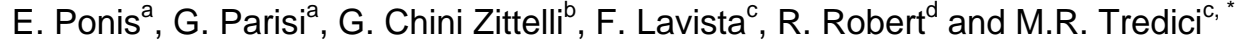 \\ a Dipartimento di Scienze Zootecniche, Università degli Studi di Firenze, Via delle Cascine 5, 50144 Firenze, Italy \\ ${ }^{b}$ Istituto per lo Studio degli Ecosistemi, CNR, Via Madonna del Piano 10, 50019 Sesto Fiorentino, Firenze, Italy \\ ${ }^{\mathrm{c}}$ Dipartimento di Biotecnologie Agrarie, Università degli Studi di Firenze, Piazzale delle Cascine 24, 50144 \\ Firenze, Italy \\ d Laboratoire de Physiologie des Invertébrés Marins, IFREMER, Presqu'île du Vivier, 29840 Landunvez, France \\ *: Corresponding author : M. Tredici, Tel.: +39 055 3288306; fax: +39 0553288272 , email address : \\ mario.tredici@unifi.it
}

\begin{abstract}
:
The haptophyte Pavlova lutheri was cultivated in a 4-I flat alveolar photobioreactor (FAP) in semicontinuous mode during 35 days, achieving a mean volumetric productivity of $0.4 \mathrm{~g} \mathrm{l}-1$ day-1. The microalgal culture was harvested from the photobioreactor at an average concentration of $3.5 \mathrm{~g} \mathrm{l}-1$ and subjected to different storage conditions in which the effects of temperature $\left(1{ }^{\circ} \mathrm{C}, 4^{\circ} \mathrm{C}\right.$ and 25 ${ }^{\circ} \mathrm{C}$ ), air supply and preservative (ascorbic or propionic acid) addition on the viability of the stored suspensions were investigated. Low temperatures $\left(1\right.$ and $\left.4{ }^{\circ} \mathrm{C}\right)$ and air-bubbling extended the shelflife of the stored suspension, while no beneficial effects of ascorbic or propionic acid were found. The influence of temperature and air-bubbling on fatty acid content and profile was also evaluated over a 23-day period of storage. Air-bubbled suspensions exhibited, on the average, a $70 \%$ decrease of total fatty acid content (TFA) during storage. Non-bubbled suspensions showed a much lower decrease. The decrease mainly involved the saturated $14: 0$ and 16:0 and the monounsaturated $16: 1 \mathrm{n}-7$ and 18:1n-9. The polyunsaturated eicosapentaenoic acid (20:5n-3; EPA) and docosahexaenoic acid (22:6n-3; DHA) decreased significantly only at the end of the storage period.

A feeding trial on Pacific oyster (Crassostrea gigas) larvae was carried out with fresh and preserved $P$. lutheri biomass kept under the best storage conditions previously defined $\left(1{ }^{\circ} \mathrm{C}\right.$; darkness; airbubbling). After 14 days of rearing no significant differences in growth or survival were detected when fresh or preserved P. lutheri was used in a monospecific diet or in association with the diatom Chaetoceros calcitrans forma pumilum.
\end{abstract}

Keywords: Algal suspensions; Preservation; Pavlova lutheri; Photobioreactor; Mollusc nutrition; Fatty acid composition; Crassostrea gigas 


\section{Introduction}

The cultivation of microalgae constitutes a fundamental step in many different domains of animal aquaculture, with particular reference to mollusc and crustacean rearing, and production of live preys for fish larvae. All these activities require the production of high quality microalgal biomass in large amounts. Although microalgae cultivation is a practice consolidated in hatcheries, several drawbacks remain, particularly those related to the culture systems currently in use. Indeed, the conventional culture techniques (batch cultures initially grown in glass carboys and then in cylinders, bags or tanks) are quite labour-intensive and biomass quality highly fluctuates between different batches. Moreover, production costs of algae biomass may account for 15 to $85 \%$ of total hatchery management costs, depending on cultivation methods and production scale (Benemann, 1992; Coutteau and Sorgeloos, 1992; Borowitzka, 1997).

Several works have been devoted to find out substitutes to fresh microalgae and a variety of different products (yeast, bacteria, microencapsulates and microparticulates, cheese whey, vegetables flours, dried or concentrated microalgae, macroalgal cell detritus) have been tested as feed for the early stages of molluscs (Coutteau and Sorgeloos, 1992; Robert and Trintignac, 1997; Knauer and Southgate, 1999; Albentosa et al., 2002; Enes and Borges, 2003; Bonaldo et al., 2005; Espinosa and Allam, 2006; Pérez Camacho et al., 2007). The adequate substitute should have appropriate size to allow ingestion and digestion, be nutritionally balanced to sustain a correct growth, be economically competitive with respect to the on-site production of algae and be able to maintain its nutritional value for a reasonable period of time, i.e., having a shelf-life spanning the hatchery-nursery-rearing cycles (Ukeles, 1975; Webb and Chu, 1983; Langdon and Siegfried, 1984; Nell, 1993; Heasman et al., 2000). Microalgal concentrates stored at low positive temperature are regarded as the most promising alternative to fresh algae and encouraging results have been obtained in feeding larval and/or juveniles stages of oysters (Donaldson, 1991; Nell and O'Connor, 1991; Knuckey and Brown, 1998; Mc Causland et al., 1999; Heasman et al., 2000; Robert et al., 2001; Brown and Robert, 2002). For example concentrates of Chaetoceros calcitrans and Skeletonema costatum obtained by centrifugation and stored at $4{ }^{\circ} \mathrm{C}$ for a period of $1-2$ weeks gave equivalent growth to fresh microalgae when used as part of a mixed diet for $C$. gigas juveniles (MC Causland et al., 1999). The main drawback of stored microalgal concentrates is related to their shelf-life, which varies largely depending upon the storage procedures and species. However, shelf-life is generally restricted. Promising results have been obtained by Montaini et al. (1995) with Tetraselmis suecica suspensions $\left(4 \mathrm{~g} \mathrm{I}^{-1}\right)$ preserved in darkness at $4{ }^{\circ} \mathrm{C}$, with no significant reduction in viability after 50 days of storage, and an unaltered fatty acid profile over 90 days. Suspensions of Nannochloropsis $\mathrm{sp}$. at different cell concentrations $\left(4,20\right.$ and $\left.60 \mathrm{~g} \mathrm{I}^{-1}\right)$ stored at $4{ }^{\circ} \mathrm{C}$, in darkness, maintained from 80 to $90 \%$ of their viability after two months of storage (Chini Zittelli et al., 2003). However, both these species, either in fresh or preserved form, have a poor food value for $C$. gigas larvae and postlarvae (Robert, 1998; Robert et al., 2001, 2002).

The harvesting procedures widely used to concentrate microalgae consist of centrifugation or flocculation. These techniques are effective, but may heavily damage the cells, especially when used to harvest naked flagellates such as $P$. lutheri or Isochrysis galbana (Heasman et al., 2000; Ponis et al., 2003a). An alternative to these methods to obtain highly concentrated suspensions could be the use of high performance (high surface-to-volume ratio and strictly controlled) photobioreactors. These systems, may be operated in batch, semi-continuous or continuous mode, and lead generally to much higher cell concentrations and volumetric productivities with respect to the conventional culture systems. The flat alveolar photobioreactor (FAP), developed in the late 1980s (Tredici et al., 1991), exhibits a surface-to-volume ratio of $160 \mathrm{~m}^{-1}$ against a surface-to-volume ratio of 2-10 $\mathrm{m}^{-1}$ of traditional systems, and allows a strict control of the main parameters $\left(\mathrm{pH}, \mathrm{pO}_{2}\right.$, temperature, irradiance per cell) that influence culture growth and the nutritional quality of the produced biomass. The FAP has been tested in the cultivation of several microalgal species of interest for aquaculture ( $T$. suecica, $P$. lutheri, Nannochloropsis sp., Chlorella sp.), achieving volumetric productivities ranging from 0.5 
to $4-5 \mathrm{~g} \mathrm{I}^{-1}$ day $^{-1}$ depending on the cultured species and irradiance (Tredici et al., 1996; Chini Zittelli et al., 2000; Ponis et al., 2006).

The haptophyte $P$. lutheri is widely used in aquaculture as live feed for marine invertebrates (molluscs, crustaceans, zooplankton) and particularly for bivalves (larvae, juveniles and broodstock) (Webb and Chu, 1983; Borowitzka 1997; Wickfors and Onho, 2001; Brown, 2002; Rico-Villa et al., 2006). This microalgal species is characterized by a high content of polyunsaturated fatty acids, especially EPA and DHA (Volkman et al., 1989), which are essential for marine animals (Kanazawa et al., 1979). Experiments carried out on Saccostrea glomerata and Pecten fumatus have pointed out the good quality of $P$. lutheri concentrates stored at low positive temperature, with some results being even superior to the fresh alga (Nell and O'Connor, 1991; Heasman et al., 2000), while such benefits have been minor with C. gigas (Ponis et al., 2003a, 2003b). However, to our knowledge, the effect of the storage conditions on the viability of this microalga has not been yet examined in detail.

This study proposes a multidisciplinary approach to this topic, focusing on three main tasks: 1) evaluation of the FAP effectiveness for $P$. lutheri cultivation in semi-continuous mode; 2 ) determination of the best storage conditions for the biomass by evaluating the effects of temperature, air-supply and addition of preservatives (ascorbic or propionic acid) on viability and fatty acid content and profile; 3 ) evaluation of the nutritional value of preserved $P$. lutheri biomass for $C$. gigas larvae.

\section{Materials and methods}

\subsection{Microalgae production}

$P$. lutheri and C. calcitrans f. pumilum were obtained from the IFREMER experimental hatchery of Argenton (Brittany, France). Both species were grown in artificial 1.5- $\mu \mathrm{m}$ filtered seawater (Adriatic Sea Equipment, Forlì, Italy), autoclaved and enriched with Conway medium nutrients (Walne, 1966). Salinity was kept at 33\%o for P.lutheri. For C. calcitrans f. pumilum, salinity was reduced to $25 \%$ by addition of distilled water and sodium metasilicate (40 $\mathrm{mg} \mathrm{l}^{-1}$ ) was provided as silica source (Laing, 1979).

Initially, cultures were grown in $125-\mathrm{ml}$ flasks and 2-I glass carboys, at $20{ }^{\circ} \mathrm{C}$ and at a light intensity of $90 \mu \mathrm{mol}$ photons $\mathrm{m}^{-2} \mathrm{~s}^{-1}$; thereafter, $P$. lutheri was transferred in a 4-I FAP (Tredici et al., 1991), while the diatom was grown in 10-I glass carboys. In the FAP temperature and $\mathrm{pH}$ were maintained at $20 \pm 0.5^{\circ} \mathrm{C}$ and $7.7 \pm 0.5$, respectively, through automatic controllers and irradiance was increased from 24 to $175 \mu \mathrm{mol}$ photons $\mathrm{m}^{-2} \mathrm{~s}^{-1}$, according to cellular density. During the first 19 days, the culture in the FAP was operated in batch; thereafter, once the culture reached a density of about $3.5 \mathrm{~g} \mathrm{I}^{-1}$, a semicontinuous harvesting regimen was adopted applying a mean dilution rate of $20 \%$ day $^{-1}$. In order to prevent nitrogen and phosphorous limitation, $\mathrm{NaNO}_{3}$ and $\mathrm{NaH}_{2} \mathrm{PO}_{4}$ were added during cultivation according to microalgal growth.

\subsection{Preservation procedures}

Four experimental trials were carried out to investigate the effect of storage on viability of $P$. lutheri suspensions. Culture aliquots $(200 \mathrm{ml}$ for trials 1 and $2,300 \mathrm{ml}$ for trials 3 and 4) collected from the FAP were dispensed in $500 \mathrm{ml}$ sterilized flasks and subjected to the different storage conditions. Culture concentration at the beginning of the storage varied between 3.15 and $3.75 \mathrm{~g} \mathrm{I}^{-1}$, corresponding to 120 and $143 \times 10^{6}$ cells mll $^{-1}$, respectively. All the storage trials were carried out in darkness.

During the first trial $P$. lutheri suspensions were stored at "room-temperature" $\left(25 \pm 1{ }^{\circ} \mathrm{C}\right)$ and the effect of air-bubbling was investigated. The effect of air-bubbling was also evaluated in the second experiment with suspensions stored at $4 \pm 2{ }^{\circ} \mathrm{C}$ (standard homerefrigerator temperature). During the third trial the role of air-supply was further investigated in suspensions maintained at $4{ }^{\circ} \mathrm{C}$ by evaluating both the physical (mixing of the culture to avoid cell settlement) and metabolic $\left(\mathrm{O}_{2}\right.$ availability) effect. To this end $P$. 
lutheri suspensions were bubbled either with air or nitrogen. Moreover, the effects of two common food preservatives, ascorbic acid (antioxidant) and propionic acid (antimicrobial), were evaluated. Both preservatives were used at concentrations typically used in human foodstuffs ( $0.03 \%$ for ascorbic acid and $0.3 \%$ for propionic acid). During the fourth experiment, in which both cell viability and fatty acid composition were followed, the effects of higher ascorbic acid concentrations $(0.09 \%$ and $0.3 \%)$ were investigated in suspensions stored at $4{ }^{\circ} \mathrm{C}$. A lower storage temperature $\left(1^{\circ} \mathrm{C}\right)$ was also tested in this trial in either static or air-bubbled cultures. All treatments were performed in duplicate.

\subsection{Feeding trials}

C. gigas larvae were obtained from a commercial hatchery (Satmar, Normandy, France) and were 72-hour old at the beginning of the trial (D-larvae). They were dispensed at a density of 5 larvae $\mathrm{ml}^{-1}$ into $2-\mathrm{I}$ glass beakers, each containing $1.8 \mathrm{I}$ of filtered $(1-\mu \mathrm{m})$ seawater (34\% salinity). The beakers were kept at $25{ }^{\circ} \mathrm{C}$. In order to limit bacterial contamination, chloramphenicol was added at $4 \mathrm{mg} \mathrm{I}^{-1}$. During the 14-day feeding trial six diets were compared: 1$)$ fresh $P$. lutheri (Pf); 2) $P$. lutheri suspensions stored with airbubbling at $1{ }^{\circ} \mathrm{C}$ in darkness (Pp); 3) C. calcitrans f. pumilum (Cp; positive control); 4) the bispecific diet $\mathrm{Pf}+\mathrm{Cp} ; 5)$ the bispecific diet $\mathrm{Pp}+\mathrm{Cp} ; 6)$ unfed larvae (negative control). $P$. lutheri suspension was from 14 to 28 days old when used in the trial, while the diatom was always delivered in fresh form. All diets were made equivalent in feed volume, based on microalgae cellular volume. One cell of $P$. lutheri was considered equivalent to two cells of $C$. calcitrans f. pumilum. Every second day, at each seawater renewal, the larvae were fed on the basis of $80 P$. lutheri cell equivalents per microliter of seawater. Bispecific diets contained $50 \%$ of $P$. lutheri and $50 \%$ of $C$. calcitrans f. pumilum. Each diet was run in triplicate.

\subsection{Analytical procedures}

Culture growth was estimated by measurement of biomass dry weight, as previously described by Ponis et al. (2003a), and by measurement of cell number using a Bürker haemocytometer. Irradiance was measured by a LI-190SB cosine quantum sensor connected to a LI-185B quantum/radiometer/photometer (Li-Cor, Inc., Lincoln, NE, USA). Viability of stored $P$. lutheri suspensions was estimated by measuring the specific oxygen evolution rate (photosynthetic activity) as described by Montaini et al. (1995). Before the measurement samples were diluted in fresh medium to a final chlorophyll concentration of 6-7 $\mathrm{\mu g} \mathrm{ml}^{-1}$ and incubated at $20^{\circ} \mathrm{C}$ for 2 hours. Oxygen evolution measurements were carried out in duplicate (four replicates per treatment) using an oxymeter (Biological Oxygen Monitor mod. 5300, Yellow Springs Instruments Co, USA), equipped with a "Clark" type electrode. Viability was expressed as percentage of the control (the algal suspension before storage). Chlorophyll content was estimated spectrophotometrically following the procedure described by Parsons and Strickland (1963).

For fatty acid determinations, samples were harvested by centrifugation and aliquots of the paste obtained were stored at $-20^{\circ} \mathrm{C}$, and then freeze-dried before extraction. Fatty acid analysis was performed as described previously (Chini Zittelli et al., 1999). Fatty acid methyl esters were analyzed using a GC Fision 8380 gas-chromatograph equipped with a hydrogen flame ionization detector and a SP 2380 column $(30 \mathrm{~m} \times 0.20 \mu \mathrm{m}$ film thickness). Samples were injected at $90^{\circ} \mathrm{C}$ and temperature was increased up to $220^{\circ} \mathrm{C}$, with a gradient of $3{ }^{\circ} \mathrm{C} \mathrm{min}^{-1}$. Helium was used as carrier gas and eptadecaenoic acid $(17: 0)$ as internal standard.

Larvae were sampled at the beginning and at the end of the trial (day 1 and day 14, respectively). At each time, at least 200 animals from each replicate were collected in order to determine shell length (defined as the antero-posterior axis parallel to the hinge). For this purpose an image analysis technique, using the SCION software (NiH Image), was employed. Larval mortality was estimated by counting translucent larval shells under the microscope, the survival rate corresponding to the complement of the mortality percentage. 
Significant differences between feeding experimental conditions were detected by means of ANOVA and Scheffe's tests $(P<0.05)$; survival data were previously transformed (arcsine square root $x_{i} 100^{-1}$ ) before statistical treatments.

\section{Results}

\subsection{Cultivation of $P$. lutheri}

The typical growth curve of $P$. lutheri cultivated in the FAP is shown in Fig. 1. During the first 19 days the culture was operated in batch mode and illumination was increased accordingly to the cellular concentration. Once the culture had reached a concentration of about $3.5 \mathrm{~g} \mathrm{I}^{-1}$ (corresponding to about $135 \times 10^{6}$ cells $\mathrm{ml}^{-1}$ ), a semi-continuous harvesting regimen (20\% daily) was adopted and kept over a 5-week period. During this second phase a mean cell concentration at harvesting of $3.1 \mathrm{~g} \mathrm{I}^{-1}$ and a mean volumetric productivity of $0.4 \mathrm{~g} \mathrm{I}^{-1}$ day-1 were attained and maintained.

\subsection{Influence of storage conditions on viability of $P$. lutheri}

The influence of storage conditions on viability of $P$. lutheri was evaluated using suspensions collected from the FAP during the second (semi-continuous harvesting) phase. During the first trial carried out at $25{ }^{\circ} \mathrm{C}$ (Fig. 2), the suspensions maintained without air-bubbling lost completely their viability in 24 hours of storage. This was confirmed by microscopic observation (cell-clumping and diffuse lysis were observed). Air-bubbled suspensions retained $42 \%$ viability after two days of storage and lost it completely after seven days.

In the second storage trial carried out at $4{ }^{\circ} \mathrm{C}$ (Fig. 3), P. lutheri suspensions without airbubbling lost more than $50 \%$ of their viability after the first day of storage. However, a residual viability higher than $40 \%$ was maintained for about one week. In air-bubbled suspensions viability increased during the first week, afterwards, it gradually declined resulting nil on day 15 .

The third trial, carried out at $4{ }^{\circ} \mathrm{C}$ (Fig. 4), clearly showed the role of oxygen supply on viability during storage. Bubbling with pure nitrogen led to a total loss of viability in five days, while all the other conditions in which air-bubbling was used, including those with ascorbic or propionic acid, exhibited a similar pattern with a $70-78 \%$ residual viability still observed after two weeks of storage.-Accordingly, no beneficial effects of preservatives was observed.

During the fourth trial (Fig. 5) the influence of higher ascorbic acid concentrations (threefold and tenfold the dose previously used) was evaluated in suspensions stored at $4{ }^{\circ} \mathrm{C}$ with air-bubbling. Moreover, a lower storage temperature $\left(1{ }^{\circ} \mathrm{C}\right)$ was tested both in static and in air-bubbled cultures. Suspensions kept at $1{ }^{\circ} \mathrm{C}$ without air-bubbling and those stored at $4{ }^{\circ} \mathrm{C}$ with air-bubbling and added with $0.3 \%$ ascorbic acid lost completely their viability in three days. The suspensions kept with air-bubbling at $1{ }^{\circ} \mathrm{C}$ surprisingly showed an enhanced viability level over the initial value, which was maintained until day 11, when accidentally the culture was lost. Good viability levels (about $80 \%$ ) were retained during the first two weeks of storage in the suspensions kept at $4{ }^{\circ} \mathrm{C}$ with airbubbling both with (0.09\%) and without ascorbic acid.

\subsection{Influence of storage conditions on fatty acid content and profile of $P$. lutheri}

Fatty acid analyses were performed on $P$. lutheri samples collected during the fourth trial. Storage significantly decreased the TFA of $P$. lutheri (Fig. 6). In particular the air-bubbled suspensions exhibited a 34-39\% decrease after one week and an about a $70 \%$ decrease after three weeks. After three weeks of storage, the static suspension lost only $30 \%$ of the TFA. All the storage conditions examined led to a significant modification of the initial fatty 
acid profile, with no effect of ascorbic acid addition. The main fatty acids found in fresh $P$. lutheri were the saturated 14:0 and 16:0, the monounsaturated 16:1n-7 and the polyunsaturated EPA, which accounted for more than 78\% of the TFA (Fig. 7). After 7 days of storage, air-bubbled suspensions (samples A, B, C, D) exhibited a significant decrease in 16:0 (53\%), 16:1n-7 (48\%) and 18:1n-9 (42\%), while the static suspension (sample E) exhibited a lower decrease of these fatty acids (12, 15 and 4\%, respectively). As far as polyunsaturated fatty acids are concerned, samples stored at $1{ }^{\circ} \mathrm{C}$ (samples $\mathrm{D}$, E) showed a significant decrease in EPA and DHA (on average $43 \%$ and $46 \%$ decrease, respectively), while a lower decrease of these fatty acids (on the average 5\%) was observed in samples stored at $4{ }^{\circ} \mathrm{C}$ (samples A, B, C).

After 23 days of storage air-bubbled samples preserved at $4{ }^{\circ} \mathrm{C}$ exhibited a large decrease of all the fatty acids, ranging from $54 \%$ for $14: 0$ to $81 \%$ for $18: 2 n-6$; in contrast a lower decrease was observed in non-bubbled suspensions stored at $1{ }^{\circ} \mathrm{C}$, with a mean loss of $27 \%$ of the unsaturated fraction, $24 \%$ of the monounsaturated fraction and $55 \%$ of the polyunsaturated fraction with respect to the fresh alga.

\subsection{Nutritional value of preserved P. lutheri for C. gigas larvae}

At the end of the feeding trial (day 14) no significant differences in shell length were found between larvae fed fresh or preserved $P$. lutheri, either as monospecific (110.0 vs. 110.4 $\mu \mathrm{m})$ or bispecific $(153.0 \mathrm{vs}$. $155.7 \mu \mathrm{m})$ diet (Table 1). The best growth occurred when $C$. calcitrans f. pumilum was added to $P$. lutheri (both fresh and preserved). A monospecific diet based on this diatom supported a similar shell growth than that obtained with the mixed diets. Survival of larvae fed single diet based on $P$. lutheri was about $70 \%$, significantly lower than that of the other groups (> 78\%).

\section{Discussion}

Several problems related to algal production in hatcheries (i.e., high-costs, high need of labour, scarce control and large variability of the quality of the produced biomass) remain nowadays unsolved. The use of high performance photobioreactors for the mass production of marine phytoplankton appears, accordingly, essential to improve hatchery efficiency (Tredici, 2004). Furthermore, the possibility to separate microalgae culture from animal rearing in terms of space (off-the-shelf production of microalgae in specialized facilities) or in terms of time (storage of the concentrated biomasses harvested in excess in the hatchery during less busy periods) could give an important contribution to hatchery profitability. To achieve this, suitable preservation methods for the produced algal biomass are necessary.

In this work $P$. lutheri, a microalga commonly used in mollusc hatcheries, was successfully produced in a flat alveolar photobioreactor (FAP) and preserved. The FAP could be operated under strictly controlled conditions and effectively produced a concentrated suspension (up to $3.8 \mathrm{~g} \mathrm{I}^{-1}$ ) of the microalga. The system reliably attained, in semi-continuous mode, daily productivities of $0.4 \mathrm{~g} \mathrm{I}^{-1}$ day $^{-1}$ for 5 weeks. Our results confirm those reported by Ponis et al. (2006) with the same organism for a longer period. Significantly higher productivities (up to $1.2 \mathrm{~g} \mathrm{I}^{-1}$ day $^{-1}$ ) were reported for $P$. Iutheri cultures grown in the same system at a higher light intensity (Tredici et al., 1996).

Different techniques have been applied for microalgal preservation, including refrigeration, freezing and drying (Knauer and Southgate, 1999). Among these, the storage at low positive temperatures has been reported to be able to preserve viability in different microalgae (Molina Grima et al., 1994; Montaini et al., 1995; Heasman et al., 2000). However, this technique is sometimes limited by reduced biomass shelf-life, which strongly depends on the algal species and on other storage conditions. Nutritional value of stored microalgal concentrates for larvae and juveniles of bivalves is quite well documented (Robert and Trintignac, 1997; Heasman et al., 2000; Ponis et al., 2003a; Espinosa and Allam, 2006), but works specifically devoted to improve preservation of 
microalgae biomass are still scarce. Heasman et al. (2000) found for $P$. lutheri concentrates stored at $2{ }^{\circ} \mathrm{C}$ in presence of ascorbic acid a $60 \%$ cell viability after 7 weeks of storage. However, the method used for the determination of cell viability (e.g., blue's Evans staining) is not reliable and does not give any information on the physiological status of the preserved cells (Molina Grima et al., 1994).

In this study the viability of preserved cells was measured as capacity to photosynthetically evolve oxygen, which has already proven to be a reliable technique (Montaini et al., 1995). During storage, $P$. lutheri suspensions kept at $25{ }^{\circ} \mathrm{C}$ or at $4{ }^{\circ} \mathrm{C}$ without air-bubbling, entirely lost their viability after 1 and 10 days of storage, respectively, showing the crucial role of air supply and of temperature. These results confirm those reported by Tredici et al. (1996) with static suspensions of $P$. lutheri preserved at $4{ }^{\circ} \mathrm{C}$ at a cell concentration of $2.0 \mathrm{~g} \mathrm{I}^{-1}$. Such premature decline in vitality seems in agreement with the loss of nutritional value found by Espinosa and Allam (2006) for the same species preserved in similar conditions. Our work demonstrates that when air-bubbling is provided during storage, $P$. lutheri shelf-life significantly increases in comparison with non-bubbled suspensions. At $4{ }^{\circ} \mathrm{C}$ high levels of viability $(>50 \%)$ are maintained for 10-20 days of storage before a gradual decline. When air-bubbling was used with suspensions preserved at $1{ }^{\circ} \mathrm{C}$ the initial level of viability was maintained or even increased over 11 days of storage. Unfortunately, due to a technical failure, this trial was prematurely interrupted.

Ascorbic (E300) and propionic (E280) acids are widely used in food industry as preservatives. In particular, ascorbic acid plays a major role in preventing lipid oxidation, while propionic acid has both bacteriostatic and fungistatic activity. In this study the use of propionic and ascorbic acids at dosages normally applied in food, neither showed any improvement in shelf-life extension (as can be seen from the viability pattern), nor preserved the nutritional quality of $P$. lutheri during storage (as can be seen from the change in fatty acid composition). A tenfold dosage of ascorbic acid had lethal effect on the cells.

The results of the four sets of experiments carried out in this work point out the relevance of air supply in extending the shelf-life of stored microalgae. This positive effect might be related to oxygen availability or to a physical effect of bubbling. The role of oxygen supply during storage resulted from the experiments in which the suspensions were bubbled with nitrogen in substitution of air, where viability was completely lost after five days. We assume that air-bubbling supplies oxygen and this supports respiration, which is essential in viability maintenance. Nevertheless, air-bubbling greatly affects the nutritional quality of $P$. lutheri biomass leading, after 23 days of storage, to a $70 \%$ reduction in total fatty acid content and to a significant alteration in the proportion of fatty acid classes, with a decrease of the saturated and monounsaturated fractions. Respiration of these latter fatty acids for the energy needs of the stored cells can explain such results.

A significant decrease of saturated and monounsaturated fatty acids has already been described by Molina Grima et al. (1994) for Isochrysis galbana cells kept at $4{ }^{\circ} \mathrm{C}$ over one month, whereas a slight increase of all fatty acids has been reported by Montaini et al. (1995) in concentrated suspensions of $T$. suecica kept at $4{ }^{\circ} \mathrm{C}$ after 90 days of storage. Such an increase was ascribed to the consumption of reserve material other than lipid (very likely carbohydrates), which led to a decrease in total dry weight and relative increase of the lipid fraction. It is worth noting that $P$. lutheri suspensions preserved at 1 ${ }^{\circ} \mathrm{C}$ without air-bubbling, that lost their viability after 3 days, showed a lower decrease of total fatty acid content and of the proportion of saturated and monounsaturated fatty acids.

Further investigation is necessary to better understand the metabolic behaviour of microalgae preserved at low positive temperatures, but the results here reported indicate that, during storage, $P$. lutheri cells take energy for maintenance from stored lipid. The use of air-bubbling enhances respiration and improves cell viability, but reduces the energy reserves and nutritional quality of the biomass.

Despite the reduction of fatty acids during storage, preserved $P$. lutheri suspensions exhibited a similar food value for $C$. gigas larvae with respect to the fresh alga. However, larval growth on a monsopecific diet of $P$. lutheri (either fresh or preserved) was poor in comparison to that of $C$. calcitrans $f$. pumilum. Nevertheless, the use of $P$. lutheri in 
association with $C$. calcitrans f. pumilum attained optimal growth and survival and seems able to ensure higher $C$. gigas larval performances during metamorphosis and settlement as described by Rico-Villa et al. (2006). The positive effect of $P$. lutheri in the mixed diet may be related to a better balance of some essential compounds, such as polyunsaturated fatty acids with particular reference to DHA and EPA, in fact $C$. calcitrans f. pumilum is deficient in EPA (Volkman et al., 1989). Investigation on the use of $P$. lutheri biomass stored at low positive temperatures as feed for $C$. gigas larvae should be carried out for longer periods, covering also the metamorphosis phase, in order to evaluate the effectiveness of such products for hatchery use.

\section{Conclusions}

The marine microalga $P$. lutheri has been successfully cultivated in a flat alveolar photobioreactor, both in batch and in semi-continuous mode, achieving high volumetric productivity and high cell concentration without the need to harvest and further concentrate the suspension. Microalgal suspensions maintained a high level of viability (10-20 days) when stored at low temperatures $\left(1^{\circ} \mathrm{C}, 4^{\circ} \mathrm{C}\right)$ with air-bubbling. The use of air-bubbling reduced the energy content and the nutritional quality of the biomass as shown by the significant decrease of fatty acid content. In spite of such loss, P. lutheri suspensions stored at $1{ }^{\circ} \mathrm{C}$ with air-bubbling obtained similar performance of the fresh microalga when tested as food for $C$. gigas larvae, either in a monospecific diet or in association with C. calcitrans f. pumilum.

\section{References}

Albentosa, M., Pérez-Camacho, A., Fernández-Reriz, M.J., Labarta, U., 2002. Wheatgerm flour in diets for Manila clam, Tapes philippinarum spat. Aquaculture 212, 335-345.

Benemann, J.R., 1992. Microalgae aquaculture feeds. J. Appl. Phycol. 4, 233-245.

Bonaldo, A., Badiani, A., Testi, S., Corso, G., Mordenti, A.L., Gatta, P.P., 2005. Use of centrifuged and preserved microalgae from feeding juvenile Manila clam (Tapes philippinarum): effects on growth and fatty acid composition. Ital. J. Anim. Sci. 4, 375-384. Borowitzka, M.A., 1997. Microalgae for aquaculture: opportunities and constraints. J. Appl. Phycol. 9, 393-401.

Brown, M.R., 2002. Nutritional value and use of microalgae in aquaculture. In: CruzSuárez, L.E., Tapia-Salazar, D., Gaxiola-Cortés, M.G., Simoes, N. (Eds.), Avances en Nutrición Acuicola. VI. Memorias del VI Simposium Internacional de Nutrición Acuicola, 36 September 2002, Cancun, Mexico, pp. 281-292.

Brown, M., Robert, R., 2002. Preparation and assessment of microalgal concentrates as feeds for larval and juvenile Pacific oyster (Crassostrea gigas). Aquaculture 207, 289309.

Chini Zittelli, G., Lavista, F., Bastianini, A., Rodolfi, L., Vincenzini, M., Tredici, M.R., 1999. Production of eicosapentaenoic acid by Nannochloropsis sp. cultures in outdoor tubular photobioreactors. J. Biotechnol. 70, 299-312.

Chini Zittelli, G., Pastorelli, R., Tredici, M.R., 2000. A Modular Flat Panel Photobioreactor (MFPP) for indoor mass cultivation of Nannochloropsis sp. under artificial illumination. J. Appl. Phycol. 12, 521-526.

Chini Zittelli, G., Rodolfi, L., Ponis, E., Tredici, M.R., 2003. Cold preservation and use of microalgae aquaculture feed. Abstract of the $5^{\text {th }}$ European Workshop on Biotechnology of Microalgae, 23-24 June 2003, Bergholz-Rehbrücke, Germany.

Coutteau, P., Sorgeloos, P., 1992. The use of algal substitutes and the requirement for live algae in hatchery and nursery rearing of bivalve molluscs: an international survey. $J$. Shellfish. Res. 11, 467-476. 
Donaldson, J., 1991. Commercial Production of Microalgae at Coast Oyster Company. In: Fulks, W., Main, K.L. (Eds.), Rotifer and Microalgae Culture Systems. Proceedings of a U.S.-Asia Workshop. The Oceanic Institute, Honolulu, Hawaii, USA, pp. 229-236.

Enes, P., Borges, M.T., 2003. Evaluation of microalgae and industrial cheese whey as diets for Tapes decussatus (L.) seed: effect on water quality, growth, survival, condition and filtration rate. Aquac. Res. 34, 299-309.

Espinosa, E.P., Allam, B., 2006. Comparative growth and survival of juvenile hard clams, Mercenaria mercenaria, fed commercially available diets. Zoo. Biol. 25, 513-525.

Heasman, M.P., Diemar, J., O'Connor, W., Sushames, T., Foulkes, L., 2000. Development of extended shelf-life microalgae concentrate diets harvested by centrifugation for bivalve molluscs - a summary. Aquac. Res. 31, 637-659.

Kanazawa, A., Teshima, S., Ono, K., 1979. Relationships between the essential fatty acid requirement of aquatic animals and their capacity for bioconversion of linoleic acid to highly unsaturated fatty acid. Comp. Biochem. Physiol. 63B, 295-298.

Knauer, J., Southgate, P.C., 1999. A review of the nutritional requirements of bivalves and the development of alternative and artificial diets for bivalve aquaculture. Rev. Fish. Sci. 7, 241-280.

Knuckey, M., Brown, M.R., 1998. Microalgal concentrates as aquaculture feeds. J. Shellfish. Res. 17, 329-330.

Laing, I., 1979. Recommended procedures for the culture of Chaetoceros calcitrans. Fish. Res. Tech. Rep. 53, 8-12.

Langdon, C.J., Siegfried, C.A., 1984. Progress in the development of artificial diets for bivalve filter feeders. Aquaculture 39, 135-153.

Mc Causland, M.A., Brown, M.R., Barrett, S.M., Diemar, J.A., Heasman, M.P., 1999. Evaluation of live microalgal pastes as supplementary food for juvenile Pacific oyster (Crassostrea gigas). Aquaculture 174, 323-342.

Molina Grima, E., Sánchez Pérez, J.A., García Camacho, F.G., Acién Fernández, D., López Alonso, D., Segura del Castillo, C.I., 1994. Preservation of the marine microalga Isochrysis galbana: influence on the fatty acid profile. Aquaculture 123, 377-385.

Montaini, E., Chini Zittelli, G., Tredici, M.R., Molina Grima, E., Fernández Sevilla, J.M., Sánchez Pérez, J.A., 1995. Long-term preservation of Tetraselmis suecica: influence of storage on viability and fatty acids profile. Aquaculture 134, 81-90.

Nell, J.A., 1993. The development of oyster diets. Aust. J. Agric. Res. 44, 557- 566.

Nell, J.A., O'Connor, W.A., 1991. The evaluation of fresh algae and stored algal concentrates as a food source for Sydney rock oyster, Saccostrea commercialis (Iredale \& Roughley). Aquaculture 99, 277-284.

Parsons, T.R., Strickland, J.D.H., 1963. Discussion of spectrophotometric determination of marine plant pigments, with revised equations for ascertaining chlorophylls and carotenoids. J. Mar. Res. 21, 155.

Pérez Camacho, J.M., Salinas, C., Delgado, M., Fuertes, C., 2007. Use of single cell detritus (SCD) produced from Laminaria saccharina in the feeding of the clam Ruditapes decussatus (Linnaeus, 1758). Aquaculture 266, 211-218.

Ponis, E., Robert, R., Parisi, G., 2003a. Nutritional value of Pavlova lutheri, Isochrysis aff. galbana clone T-Iso and Chaetoceros calcitrans forma pumilum, either fresh or preserved, for larval and post-larval development of Pacific oyster (Crassostrea gigas). Aquaculture 221, 491-505.

Ponis, E., Robert, R., Parisi, G., Tredici, M.R., 2003b. Assessment of the performance of Pacific oyster (Crassostrea gigas) larvae fed with fresh and preserved Pavlova lutheri concentrates. Aquac. Int. 11, 69-79.

Ponis, E., Parisi, G., Le Coz, J.R., Robert, R., Chini Zittelli, G., Tredici, M.R., 2006. Effect of the culture system and culture technique on biochemical characteristics of Pavlova lutheri and its nutritional value for Crassostrea gigas larvae. Aquac. Nutr. 12, 322-329.

Rico-Villa, B., Le Coz, J.R., Mingant, C., Robert, R., 2006. Influence of phytoplankton diet mixtures on microalgae consumption, larval development and settlement of the Pacific oyster Crassostrea gigas (Thunberg). Aquaculture 256, 377-388.

Robert, R., 1998. Nutritional inadequacy of Nannochloris atomus and Stichoccocus bacillaris for the oyster Crassostrea gigas larvae. Haliotis 27, 29-34. 
Robert, R., Trintignac, P., 1997. Substitutes for live microalgae in mariculture: a review. Aquat. Living Resour. 10, 315-327.

Robert, R., Parisi, G., Rodolfi, L., Poli, B.M., Tredici, M.R., 2001. Use of fresh and preserved Tetraselmis suecica for feeding Crassostrea gigas larvae. Aquaculture 192, 333-346.

Robert, R., Parisi, G., Pastorelli, R., Poli, B.M., Tredici, M.R., 2002. The food quality of Tetraselmis suecica slurry for Crassostrea gigas spat. Haliotis 31, 53-56.

Tredici, M.R., 2004. Mass production of microalgae: photobioreactors. In: Richmond, A. (Ed), Handbook of Microalgal Cultures, Biotechnology and Applied Phycology. Blackwell, Oxford, pp. 178-214.

Tredici, M.R., Carlozzi, P., Chini Zittelli, G., Materassi, R., 1991. A vertical alveolar panel (VAP) for outdoor mass cultivation of microlagae and cyanobacteria. Bioresour. Technol. 38, 153-159.

Tredici, M.R., Chini Zittelli, G., Montaini, E., 1996. Cold preservation of microalgae aquaculture feeds. Refrigeration and Aquaculture. Proceedings of Refrigeration Science and Technology, 20-22 March 1996, Bordeaux, France, pp 25-32.

Ukeles, R., 1975. Views on bivalve nutrition. Proceedings of the First International Conference on Aquaculture Nutrition. University of Delaware, Newark, DE, pp. 127-162.

Volkman, J.K., Jeffrey, S.W., Nichols, P.D., Rogers, G.I., Garland, C.D., 1989. Fatty acid composition of 10 species of microalgae used in mariculture. J. Exp. Mar. Biol. Ecol. 128, 219-240.

Walne, P.R., 1966. Large scale culture of Ostrea edulis L. larvae. Fish. Invest. II 25 (4), 152.

Watson, R.H., 1986. Instant food for bivalve hatcheries. Aquaculture Digest, September, 6-9.

Webb, K.L., Chu, F.L.E., 1983. Phytoplankton as a food source for bivalve larvae. Proceedings of the Second International Conference on Aquaculture Nutrition: Biochemical and Physiological Approaches to Shellfish Nutrition. World Mariculture Society Sp. Publ. No. 2. Louisiana State University, pp. 272-291.

Wikfors, G.H., Ohno, M., 2001. Impact of algal research in aquaculture. J. Phycol. 37, 968-974.

Table 1. Shell length (mean $\pm S D ; n \geq 200$ per replicate) and survival rate (mean $\pm S D$ ) of C. gigas larvae fed different diets. Initial shell length was $88.68 \pm 3.22 \mu \mathrm{m}$. Values within the same column sharing a common superscript letter are not significantly different $(P>0.05)$.

\begin{tabular}{lll}
\hline Diet & $\begin{array}{l}\text { Shell length } \\
(\mu \mathrm{m})\end{array}$ & $\begin{array}{l}\text { Survival } \\
(\%)\end{array}$ \\
\hline $\mathrm{Pf}$ & $110.0 \pm 10.8^{\mathrm{b}}$ & $70.5 \pm 1.3^{\mathrm{b}}$ \\
\hline $\mathrm{Pp}$ & $110.4 \pm 9.9^{\mathrm{b}}$ & $70.6 \pm 2.6^{\mathrm{b}}$ \\
$\mathrm{Cp}$ & $142.1 \pm 28.3^{\mathrm{a}}$ & $80.8 \pm 1.2^{\mathrm{a}}$ \\
$\mathrm{Pf}+\mathrm{Cp}$ & $153.0 \pm 23.6^{\mathrm{a}}$ & $83.7 \pm 0.8^{\mathrm{a}}$ \\
$\mathrm{Pp}+\mathrm{Cp}$ & $155.7 \pm 10.8^{\mathrm{a}}$ & $83.0 \pm 0.2^{\mathrm{a}}$ \\
Unfed & $94.5 \pm 2.0$ & $78.6 \pm 0.6^{\mathrm{a}}$ \\
\hline
\end{tabular}

$\mathrm{Pf}=$ fresh $P$. lutheri; $\mathrm{Pp}=$ preserved $P$. Iutheri; $\mathrm{Cp}=C$. calcitrans $\mathrm{f}$. pumilum; Unfed $=$ starved larvae. 
Fig. 1. Growth of $P$. lutheri cultivated in the flat alveolar photobioreactor (FAP). Arrows indicate the change of irradiance. Initial irradiance was $24 \mu \mathrm{mol}$ photons $\mathrm{m}^{-2} \mathrm{~s}^{-1}$.

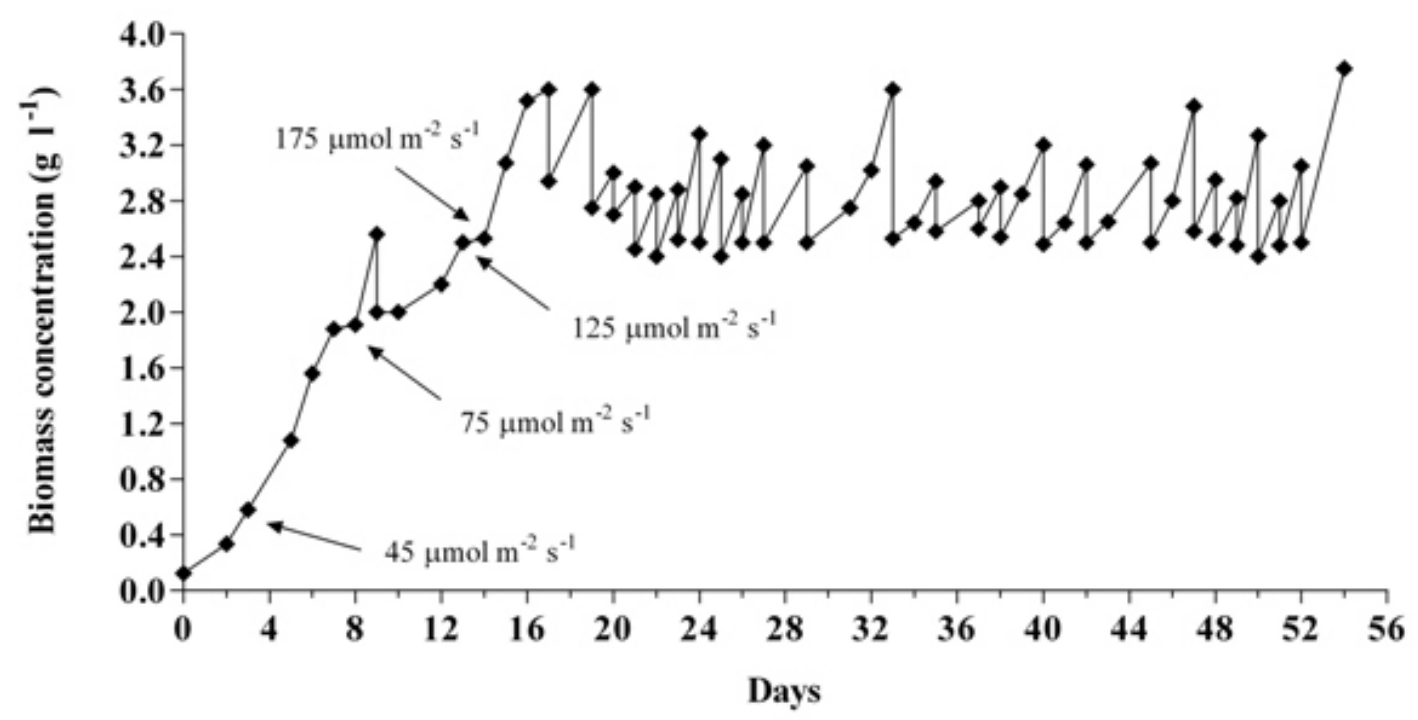

Fig. 2. Viability of $P$. lutheri suspensions preserved at $25{ }^{\circ} \mathrm{C}$ (first trial). ( $\left.\mathbf{}\right)$ without airbubbling; ( $\mathbf{\Delta})$ with air-bubbling.

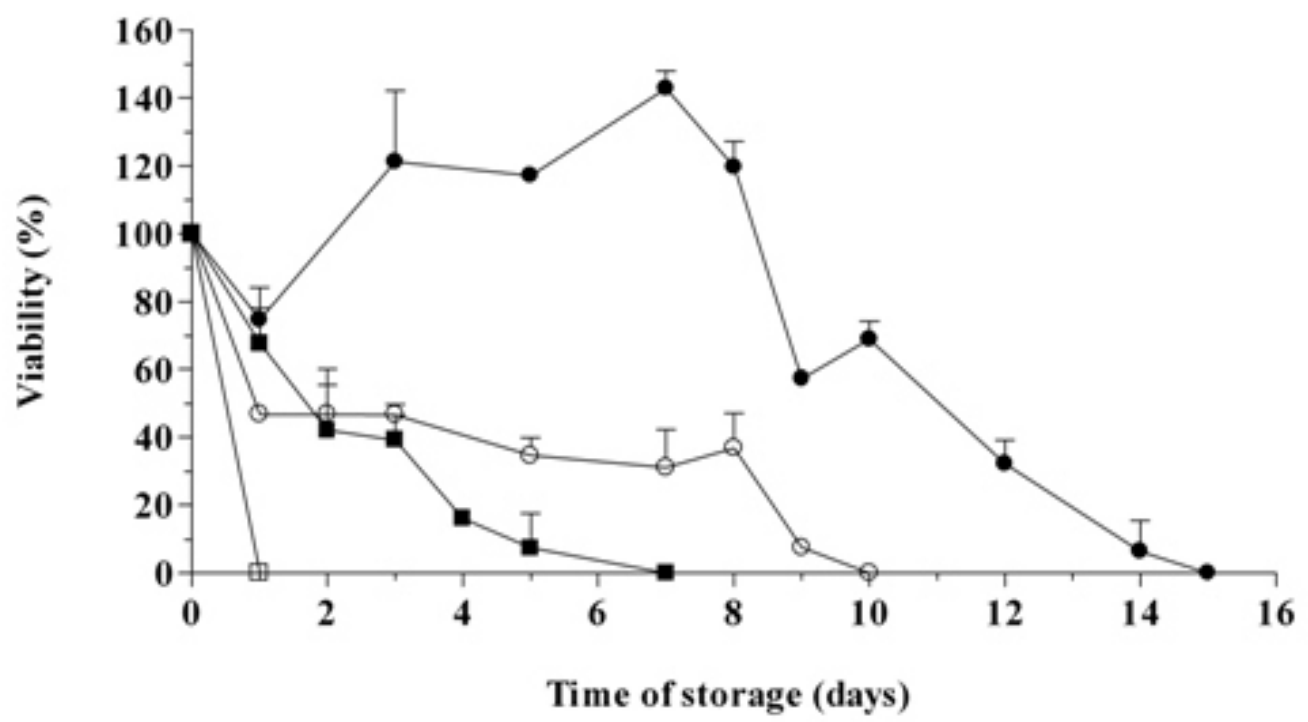


Fig. 3. Viability of $P$. lutheri suspensions preserved at $4{ }^{\circ} \mathrm{C}$ (second trial). ( $\left.\mathbf{m}\right)$ without airbubbling; ( $\mathbf{\Lambda})$ with air-bubbling.

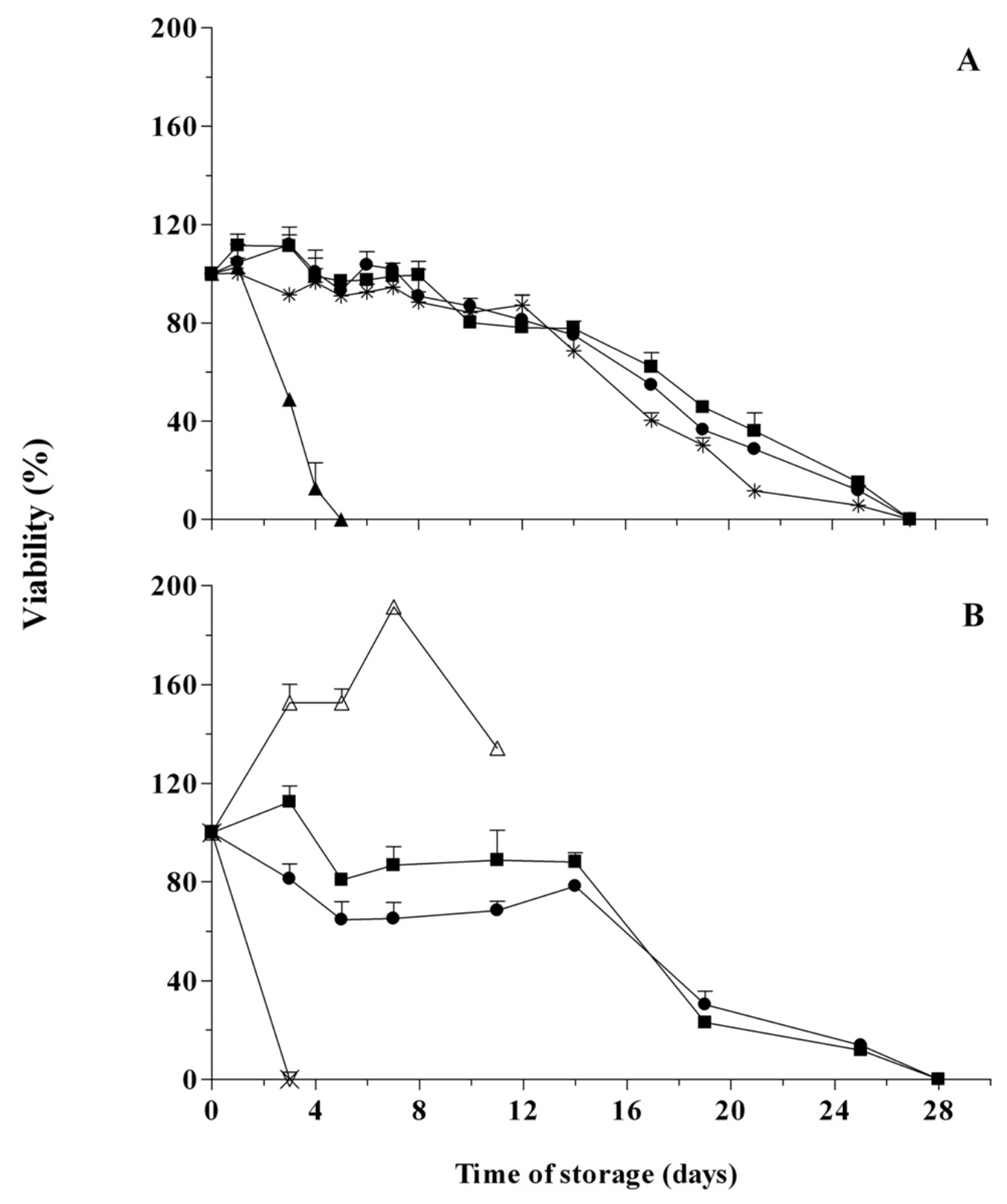


Fig. 4. Viability of $P$. lutheri suspensions preserved at $4{ }^{\circ} \mathrm{C}$ (third trial). ( $\mathbf{m}$ ) with airbubbling; ( $\boldsymbol{\Delta})$ with nitrogen-bubbling; $(\bullet)$ with air-bubbling and addition of $0.03 \%$ ascorbic acid; (*) with air-bubbling and addition of $0.3 \%$ propionic acid.

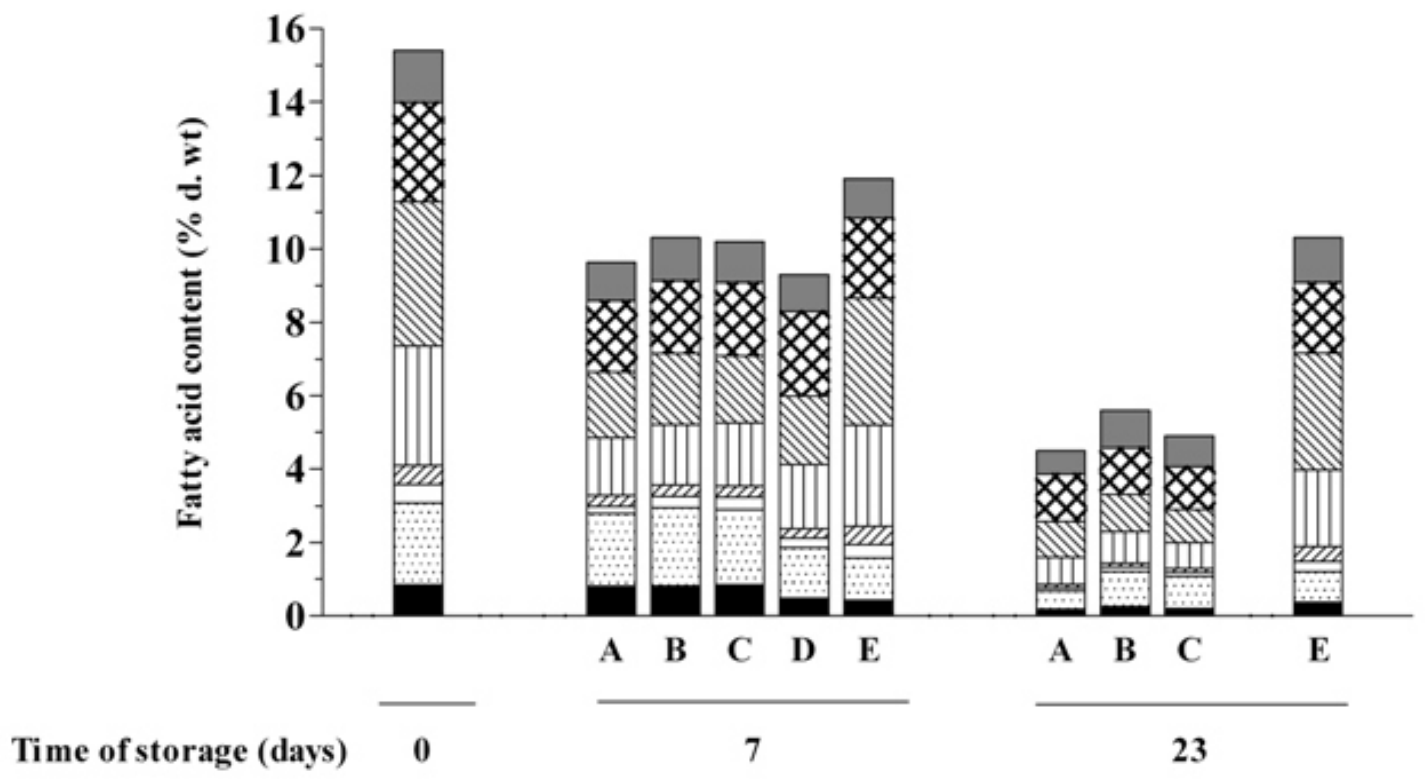

\begin{tabular}{|c|c|c|c|}
\hline & $\square 20: 5 n-3$ & $\square$ 18:2n-6 & DIII 18:1n-9 \\
\hline $16: 1 n-7$ & $16: 0$ & $X X \times 14: 0$ & others \\
\hline
\end{tabular}


Fig. 5. Viability of $P$. lutheri suspensions preserved at 1 and $4{ }^{\circ} \mathrm{C}$ (fourth trial). (a) $4{ }^{\circ} \mathrm{C}$ with air-bubbling; ( $\mathbf{\Delta}) 4{ }^{\circ} \mathrm{C}$ with air-bubbling and $0.09 \%$ ascorbic acid; $(\diamond) 4{ }^{\circ} \mathrm{C}$ with airbubbling and $0.3 \%$ ascorbic acid; (*) $1{ }^{\circ} \mathrm{C}$ with air-bubbling; $(\bullet) 1{ }^{\circ} \mathrm{C}$ without airbubbling. The lines showing viability change at $4{ }^{\circ} \mathrm{C}$ with air-bubbling and $0.3 \%$ ascorbic acid, and at $1{ }^{\circ} \mathrm{C}$ without air-bubbling are superimposed.

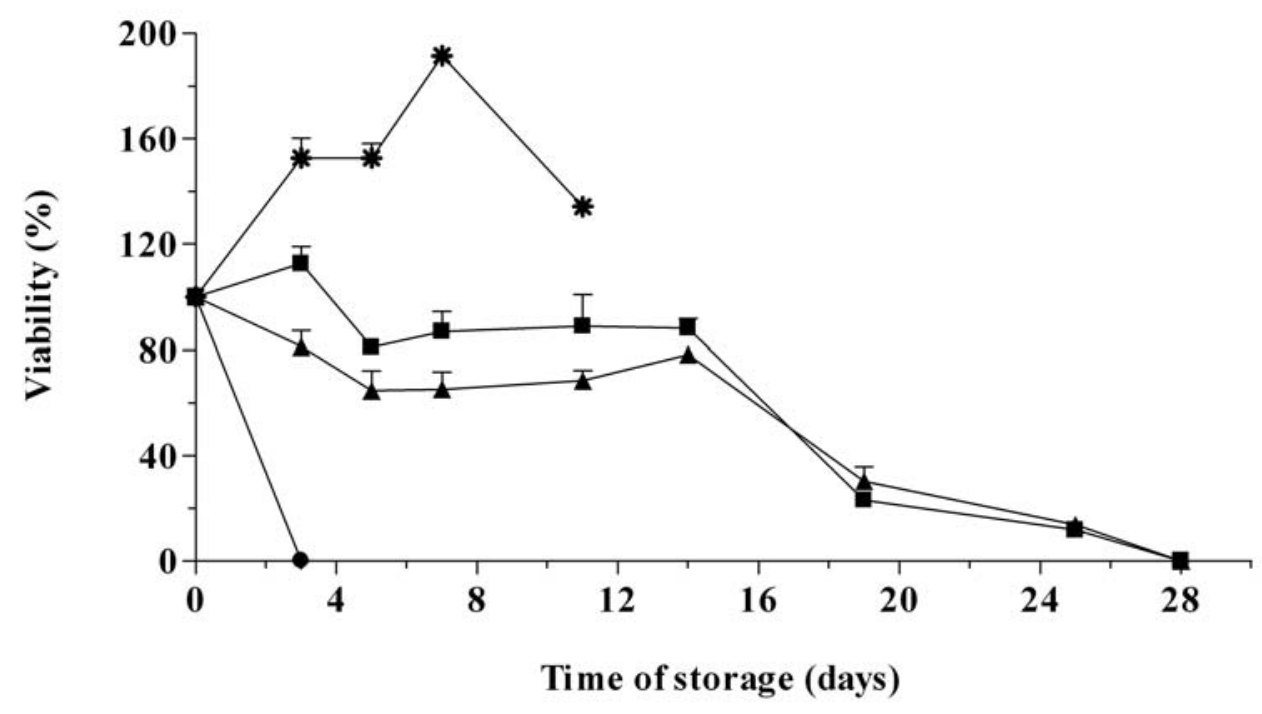

Fig. 6. Variation of total fatty acid content in $P$. lutheri suspensions during the fourth trial of storage. ( $\mathbf{\square} 4{ }^{\circ} \mathrm{C}$ with air-bubbling; ( $\left.\mathbf{\Delta}\right) 4{ }^{\circ} \mathrm{C}$ with air-bubbling and $0.09 \%$ ascorbic acid; $(\diamond) 4{ }^{\circ} \mathrm{C}$ with air-bubbling and $0.3 \%$ ascorbic acid; (*) $1{ }^{\circ} \mathrm{C}$ with air-bubbling; (•) $1{ }^{\circ} \mathrm{C}$ without air-bubbling.

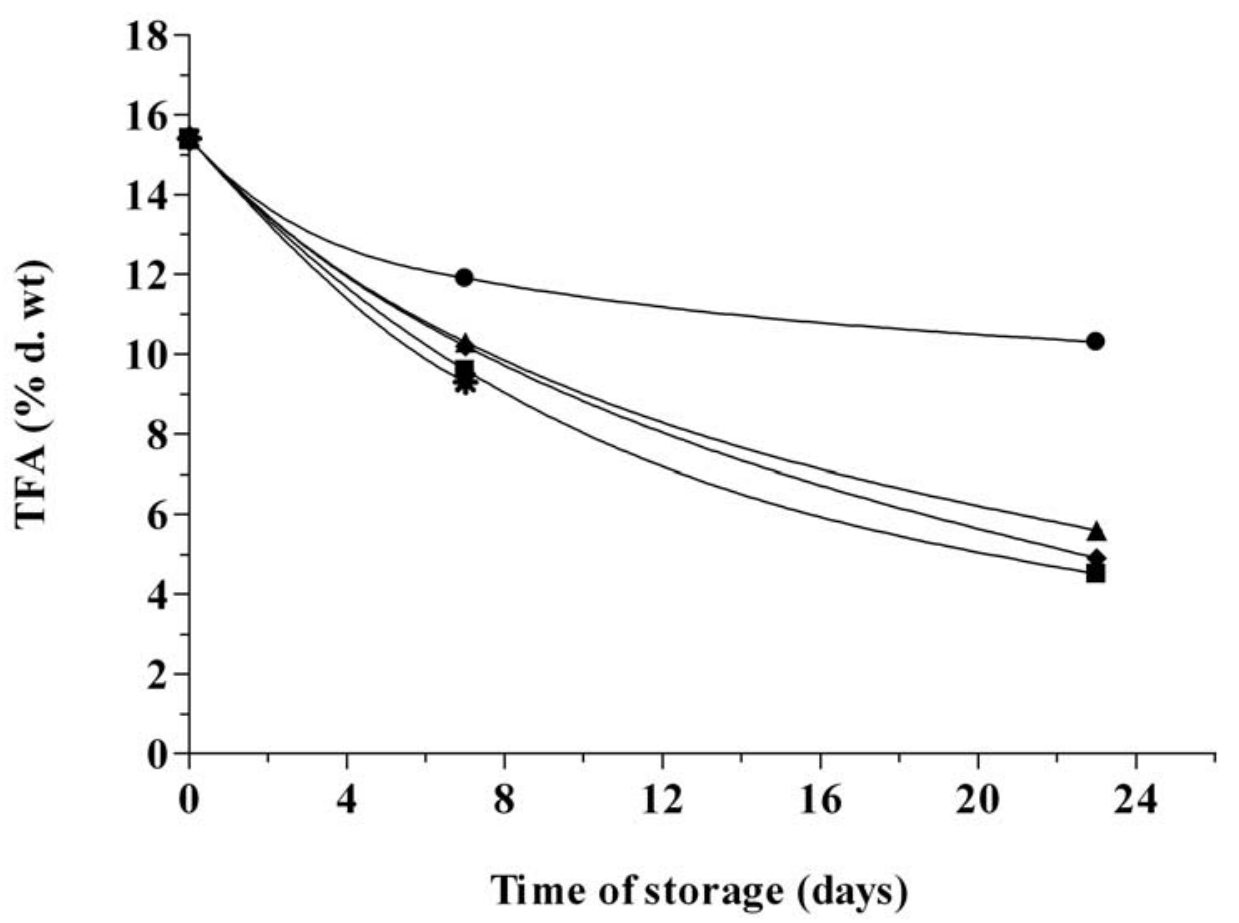


Fig. 7. Influence of storage time and conditions on fatty acid composition (\% of dry weight) of $P$. lutheri suspensions. $\mathrm{A}=$ samples kept at $4{ }^{\circ} \mathrm{C}$ with air-bubbling; $\mathrm{B}=$ samples kept at $4{ }^{\circ} \mathrm{C}$ with air-bubbling and $0.09 \%$ ascorbic acid; $\mathrm{C}=$ samples kept at $4{ }^{\circ} \mathrm{C}$ with airbubbling and $0.3 \%$ ascorbic acid; $\mathrm{D}=$ samples kept at $1{ }^{\circ} \mathrm{C}$ with air-bubbling. $\mathrm{E}=$ samples kept at $1{ }^{\circ} \mathrm{C}$ without air-bubbling.

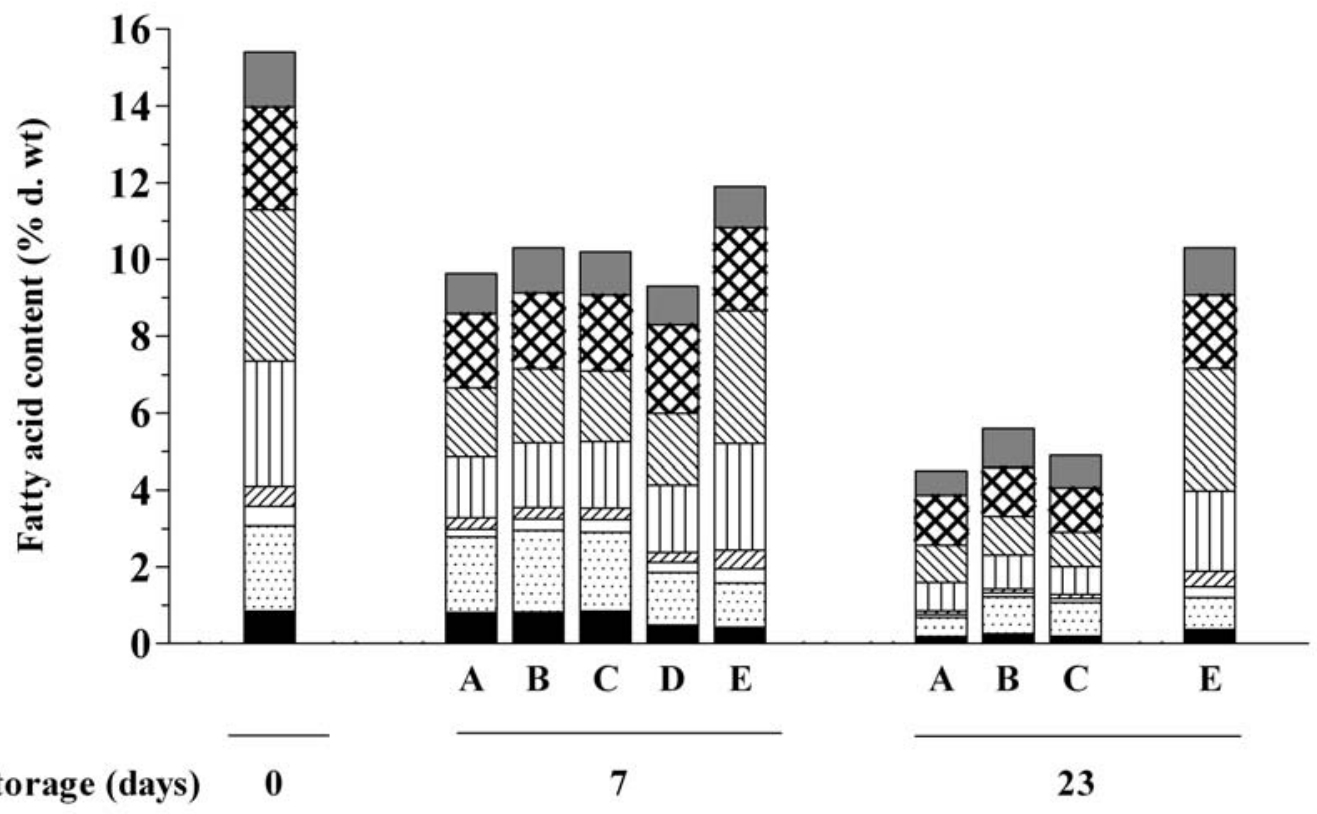

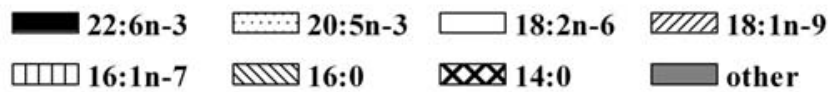

